\title{
Hydrophobic cellulose nanopaper through a mild esterification procedure
}

\section{Journal Article}

Author(s):

Sehaqui, Houssine; Zimmermann, Tanja; Tingaut, Philippe

Publication date:

2014

Permanent link:

https://doi.org/10.3929/ethz-b-000080897

Rights / license:

In Copyright - Non-Commercial Use Permitted

Originally published in:

Cellulose 21(1), https://doi.org/10.1007/s10570-013-0110-5 


\title{
Hydrophobic cellulose nanopaper through a mild esterification procedure
}

\author{
Houssine Sehaqui • Tanja Zimmermann • \\ Philippe Tingaut
}

Received: 11 September 2013/Accepted: 7 November 2013/Published online: 19 November 2013

(C) Springer Science+Business Media Dordrecht 2013

\begin{abstract}
Films of cellulose nanofibrils (CNF) (referred to as nanopaper) present a great potential in many applications due to the abundance, low environmental impact, excellent oxygen barrier properties and good mechanical performance of CNF. However, the strong hygroscopic character of the natural nanofibers limits their use in environments with high relative humidity. In this paper, we introduce a simple route for the esterification and processing of $\mathrm{CNF}$ with the aim of reducing their hydrophilicity, and producing hydrophobic cellulose nanopaper with reduced moisture sensitivity. The preparation steps of hydrophobic nanopapers involve vacuum filtration, solvent exchange from water to acetone, and reaction with anhydride molecules bearing different hydrophobic alkyl chains by hot pressing. Porous films having a surface area between 38 and $47 \mathrm{~g} / \mathrm{m}^{2}$ and pore sizes in the 3-200 nm range are obtained. This method preserves the crystalline structure of native cellulose, and successfully introduces hydrophobic moieties on CNF surface as confirmed by FTIR, XPS and elemental
\end{abstract}

Electronic supplementary material The online version of this article (doi:10.1007/s10570-013-0110-5) contains supplementary material, which is available to authorized users.

H. Sehaqui $(\bowtie) \cdot$ T. Zimmermann · P. Tingaut

Applied Wood Materials Laboratory, Empa,

Swiss Federal Laboratories for Materials Science

and Technology, Überlandstrasse 129, 8600 Dübendorf,

Switzerland

e-mail: houssine.sehaqui@empa.ch analysis. As a result, modified nanopapers have a reduced moisture uptake, both higher surface water contact angle and wet tensile properties as compared with reference non-modified nanopaper, thus illustrating the benefit of the modification for the use of cellulose nanopaper in humid environments.

Keywords Cellulose nanofibrils · CNF · Esterification · Hydrophobic · Nanopaper · Mechanical properties

\section{Introduction}

Materials from renewable resources are an interesting alternative to oil-based materials due to their availability, renewability and reduced environmental footprint. Cellulose nanofibrils (CNF) obtained by a mechanical disintegration process of plant biomass (Turbak et al. 1983; Henriksson et al. 2007; Saito et al. 2007) are of particular interest. CNF consist of high aspect ratio fibrils where the diameter is below $100 \mathrm{~nm}$ and the length is of few microns. Owing to their network forming ability and high modulus of ca $100 \mathrm{GPa}$ (Cheng et al. 2009), CNF can be processed into strong and tough materials such as films (Henriksson et al. 2008; Sehaqui et al. 2010a), membranes (Sehaqui et al. 2011b, 2012a), cellular foams (Sehaqui et al. 2010b), fibrillar aerogels (Sehaqui et al. 2011c; Saito et al. 2011; Paakko et al. 2008; Gebald et al. 2011) or can be used as reinforcing element in 
biocomposites (Sehaqui et al. 2011a, d; Zimmermann et al. 2004; Tingaut et al. 2010).

Films from CNF, here defined as nanopapers, can be prepared by different methods including vacuum filtration (Henriksson et al. 2008; Sehaqui et al. 2010a), pressure filtration (Ho et al. 2012b; Österberg et al. 2013; Ho et al. 2012a), solvent casting (Taniguchi and Okamura 1998; Sehaqui et al. 2010a), hot pressing (Ho et al. 2012b; Sehaqui et al. 2010a) and possibly by drying the CNF suspension in a continuous rolling process. In the nanopaper, CNF are tightly packed in a predominantly random $2 \mathrm{D}$ structure and interact strongly with each other, therefore greatly contributing to the excellent nanopaper's mechanical properties (Henriksson et al. 2008; Sehaqui et al. 2010a; Saito et al. 2009). Hence, tensile strength and stiffness values as high as $230 \mathrm{MPa}$ and $13 \mathrm{GPa}$ have been respectively reported for low porosity nanopaper (Sehaqui et al. 2011a), and could be further enhanced to $400 \mathrm{MPa}$ and $46 \mathrm{GPa}$ respectively by partially aligning the fibrils in the film (Sehaqui et al. 2012b; Gindl et al. 2012). Moreover, the tight packing of the nanofibers inside the films is known to confer other interesting advantages to NFC films such as high barrier properties towards oxygen (Liu et al. 2011; Fukuzumi et al. 2009) and water vapour, optical transparency (Nogi et al. 2009; Fukuzumi et al. 2009) as well as low thermal expansion (Fukuzumi et al. 2009; Yano et al. 2005). Consequently, CNF nanopapers seem to represent a green and viable alternative to films from non-renewable resources for many applications including food packaging or electronic displays.

But due to the very high hygroscopic character of the cellulose nanofibers, the properties of the nanopapers are negatively affected when the films are exposed to water or environments with very high relative humidity $(\mathrm{RH})$. Hence, the interfibrillar bonds between adjacent nanofibers are weakened by the intercalation of water molecules between cellulosic chains, which therefore leads to a decrease of the films' mechanical and barrier properties. Wet tensile strength and stiffness values of only 20 and $625 \mathrm{MPa}$ respectively have recently been reported for low porosity $\mathrm{CNF}$ nanopaper immersed in water, which represented a reduction of more than one order of magnitude compared to the tensile properties measured at $50 \%$ RH (Sehaqui et al. 2013). Moreover, a decrease in barrier performances towards oxygen and water vapour has also been reported for films exposed to environments with a RH above $80 \% \mathrm{RH}$ (Liu et al. 2011; Aulin et al. 2012).

In order to expand the use of cellulose nanopapers in applications where high RHs are required, the chemical functionalization of CNF with hydrophobic moieties seems to represent a promising approach, as this pathway should decrease the natural nanofibers' hygroscopicity and further reduce the moisture sensitivity of the resulting films exposed to high RHs or liquid water.

The functionalization of cellulose nanofibers, such as CNF or shorter cellulose nanocrystals, has already been reported in the literature in order to tailor their surface properties. Two main approaches have been used so far to functionalize the surface of the nanofibers, namely the non-covalent adsorption of molecules through physical and chemical processes or the covalent attachment of hydrophobic entities (Tingaut et al. 2012). From this last approach, esterification (Tingaut et al. 2010; Cetin et al. 2009), silylation (Gousse et al. 2002), amidation (Lasseuguette 2008; Johnson et al. 2011), and polymer grafting (Boujemaoui et al. 2012; Habibi et al. 2008; Habibi and Dufresne 2008) have widely been investigated for various purposes including the possibility to disperse the nanofibers in low polar solvents (Tingaut et al. 2010; Cetin et al. 2009; Lasseuguette 2008; Johnson et al. 2011; Araki et al. 2001), an improvement of the nanofibers' compatibility with hydrophobic polymer matrices (Tingaut et al. 2010; Siqueira et al. 2009), hydrophobization (Johnson et al. 2011; Littunen et al. 2011), and moisture uptake reduction (Boujemaoui et al. 2012).

In the present work, we aim to elaborate functionalized nanopaper showing reduced moisture sensitivity and therefore enhanced mechanical properties in humid environments as compared with pristine nanopapers. A mild chemical functionalization approach is used. The covalent grafting of hydrophobic entities onto the surface of cellulose nanofibers is preferred here instead of physical/chemical adsorption processes, as a covalent attachment is often associated with a reduced probability of leaching in wet conditions. Unmodified CNF are used as initial building blocks and are further modified with anhydrides with different carbon chain lengths in order to elaborate functionalized nanopapers. The innovative character of the present work compared to previously reported works on hydrophobic nanopaper lies in the use of 
benign solvents and a hot-pressing method for simultaneously conducting the reaction and shaping the nanopaper, while in other works, the reaction was conducted on nanofibers in solution and followed by processing the nanofibers into nanopaper (Missoum et al. 2012; Rodionova et al. 2011). In the first part of this paper, the chemical modification and the characterization of the resulting CNF materials is presented. In the second part, the impact of the chemical functionalization on the properties of the resulting hydrophobized nanopapers is further evaluated in terms of moisture uptake, wetting characteristics and mechanical properties at different RH's.

\section{Materials and methods}

Cellulose pulp powder produced from oat straw with a hemicellulose content of $22.6 \%$ and $0.2 \%$ residual lignin (Jelucel OF300, Rosenberg, Germany) was used as starting raw material for the production of CNF. The anhydrides used for the esterification reaction, namely acetic anhydride, butyric anhydride, hexanoic anhydride and 2 dodecen-1-yl-succinnic anhydride were purchased from Sigma Aldrich and used as received.

\section{CNF disintegration}

CNF were obtained by disintegration of oat straw (Jelucel OF300, Rosenberg, Germany) using a two-steps mechanical treatment, including a refining step using an inline dispersing system at 20,000 rpm for $2 \mathrm{~h}$ (Megatron MT 3000, Kinematica AG, Switzerland) followed by a mechanical disintegration step with a high pressure homogenizer (lab-scale Microfluidizer type M-110Y, Microfluidics Corporation, USA). The suspension was first pumped through two consecutive chambers of 400 and $200 \mu \mathrm{m}$ (i.e., H230Z400 and H30Z200, respectively) for 12 passes, and second through two consecutive chambers of 200 and $75 \mu \mathrm{m}$ (i.e., H30Z200 and F20Y75 chambers, respectively) for 16 passes. Pressure up to $100 \mathrm{MPa}$ was applied to generate high shear stress on the cellulose fibers (Zimmermann et al. 2010).

Preparation of the modified nanopaper

A CNF aqueous suspension (ca. $300 \mathrm{mg}$ solid content of cellulose) was diluted to $0.1 \mathrm{wt} \%$ and filtered on top of a $0.65 \mu \mathrm{m}$ filter membrane (DVPP, Millipore) until a strong "cake" was formed. The cake was solvent exchanged into acetone by 4 successive overnight immersions. After the last immersion, the cake consisting of $\mathrm{CNF}$ in acetone was soaked in the anhydride reagent for 2 days. The anhydride with the longest carbon chain (2 dodecen-1-yl-succinnic anhydride) was in solid form and was therefore dissolved in acetone ( $5 \mathrm{~g}$ into $50 \mathrm{ml}$ ) before immersing the cake into it.

To conduct the reaction, the cake was removed from the reactive solution and placed between two porous metallic sheets each covered with a tissue paper, and introduced in an oven at $80{ }^{\circ} \mathrm{C}$ for $2 \mathrm{~h}$ with a $10 \mathrm{~kg}$ weight on top (pressure of $2 \mathrm{~N} \mathrm{~cm}^{-2}$ ). This was followed by thorough washing with acetone and then ethanol by immersions overnight, and finally oven drying at $60{ }^{\circ} \mathrm{C}$ for $3 \mathrm{~h}$ under a weight of $10 \mathrm{~kg}$.

The preparation procedure from the isolated nanofibers to the hydrophobic nanopaper took about 1 week since the solvent exchanges and the washings were performed overnight.

For comparison, a reference nanopaper was prepared by vacuum filtration of a CNF aqueous suspension on top of a $0.65 \mu \mathrm{m}$ filter membrane (DVPP, Millipore), followed by solvent exchange to ethanol, and finally oven drying at $60{ }^{\circ} \mathrm{C}$ for $3 \mathrm{~h}$ under a weight of $10 \mathrm{~kg}$. Washing with acetone was not used for the reference nanopaper since there was no need to extract non-reacted species as in the case of modified nanopapers.

\section{FTIR (ATR)}

Infrared spectra of reference and modified CNF nanopapers were recorded using a FTS 6,000 spectrometer (Portmann Instruments AG, Biel-Benken, Switzerland). For each sample, the diamond crystal of an attenuated total reflectance (ATR) accessory was brought into contact with the surface of the sample to be analyzed. The contact area was about $2 \mathrm{~mm}^{2}$, and a torque of $10 \mathrm{cN} \mathrm{m}$ was used to ensure the same pressure on each sample. All spectra were recorded between 4,000 and $600 \mathrm{~cm}^{-1}$ with a resolution of $4 \mathrm{~cm}^{-1}$ and 32 scans. All FTIR spectra were normalised with respect to the peak located at $897 \mathrm{~cm}^{-1}$ corresponding to the $\mathrm{C}-\mathrm{O}-\mathrm{C}$ stretching vibration of the cellulose $\beta$ - $(1 \rightarrow 4)$-glucosidic linkage (Nelson and O'Connor 1964). This peak was not affected by 
the chemical modification in the conditions used in our study.

\section{Elemental analysis}

Microelemental analyses of carbon and hydrogen in the nanopapers were performed by the microelemental laboratory of ETH Zurich on a LECO CHN-900 instrument (Leco Corporation, St. Joseph, MI, USA). The combustion products $\mathrm{CO}_{2}$ and $\mathrm{H}_{2} \mathrm{O}$ were analyzed quantitatively by infrared spectroscopy in order to determine the content of carbon and hydrogen, respectively. The carbon contents of the reference and modified CNF samples were corrected with respect to the theoretical value of cellulose $(44.44 \%)$ and the degree of substitution was calculated from the corrected carbon weight content $(\% \mathrm{C})$ using the Eq. (1) (see also supplementary information $\mathrm{S} 1$ ).

$D S=\frac{72-162 \% C}{12 C_{g}(\% C-1)+16 \% C . O_{g}-\% C . H_{g}-\% C}$

with $\mathrm{C}_{\mathrm{g}}, \mathrm{H}_{\mathrm{g}}$ and $\mathrm{O}_{\mathrm{g}}$ being the number of carbon, hydrogen and oxygen in the grafted entity. Details of the DS equation can be found in Supplementary Information (See S1).

\section{XPS analysis}

The spectra were acquired on a physical electronics (PHI) quantum 2000 photoelectron spectrometer using monochromated $\mathrm{Al}-\mathrm{K} \alpha$ radiation generated from an electron beam operating at $15 \mathrm{kV}$ and $25 \mathrm{~W}$, using the same parameters as described elsewhere (Tingaut et al. 2011). The binding energy scale was calibrated for $\mathrm{Au}$ $4 \mathrm{f}_{7 / 2}$ electrons to be at $84.0 \pm 0.1 \mathrm{eV}$. The electron take-off angle was $45^{\circ}$ and the analyzer was operated in the constant pass energy mode of $117.4 \mathrm{eV}$ (calibrated to a total analyzer energy resolution of $1.62 \mathrm{eV}$ for $\mathrm{Ag}$ $3 \mathrm{~d}$ electrons) for survey scans. The detail scans (high resolution scans) of the $\mathrm{C}_{1 \mathrm{~s}}$ and $\mathrm{O}_{1 \mathrm{~s}}$ signals were measured at an analyzer pass energy of $46.95 \mathrm{eV}$ resulting in a spectrometer resolution of $0.95 \mathrm{eV}$. Surface charging during spectra acquisition was compensated by simultaneous operation of an electron and an argon ion neutralizer, while the binding energies of all spectra were shifted so that the $\mathrm{O}_{1 \mathrm{~s}}$ signal was at $533.2 \mathrm{eV}$, the reference position for cellulose.
Analysis of the XPS spectra was performed using the MultiPak 6.1A software provided by the instrument's manufacturer, Physical Electronics. Surface elemental concentrations and $\mathrm{O} / \mathrm{C}$ ratios were calculated from the low resolution survey spectra, using the predefined sensitivity factors in the MultiPak 6.1A software.

X-ray diffraction analysis (XRD)

XRD patterns on cellulose films were obtained using a PANalytical X'Pert PRO $\theta-2 \theta$ MPD system $(\mathrm{Cu}-\mathrm{K} \alpha$ radiation, $1.5418 \AA$ ). The diffraction patterns were recorded from $5^{\circ}$ to $50^{\circ}$ in $2 \theta$ with an angular step interval of $0.025^{\circ}$. From XRD spectra, the crystallinity indexes of unmodified and modified nanopapers were calculated by using the XRD peak height method (Eq. 2) (Park et al. 2010).

$C I=\left(1-\frac{I_{1}}{I_{2}}\right) \times 100 \%$

where $I_{1}$ is the minimum intensity of the amorphous phase $\left(2 \theta-19^{\circ}\right)$ and $I_{2}$ is the intensity associated with the crystalline region of cellulose $\left(2 \theta-22.5^{\circ}\right)$.

\section{Scanning electron microscopy}

A drop of a diluted and ultra-turrax treated (10 $\mathrm{min}$ at $11,000 \mathrm{rpm})$ aqueous CNF suspension (0.05\% w/w) and small pieces of CNF films were placed on a specimen holder. All samples were directly sputtercoated with a platinum layer of about $7.5 \mathrm{~nm}$ (BALTEC MED 020 Modular High Vacuum Coating Systems, BAL-TEC AG, Liechtenstein) in Ar as a carrier gas at $5 \times 10^{-2}$ mbar. SEM was carried out using a FEI Nova NanoSEM 230 instrument (FEI, Hillsboro, Oregon, USA). SEM images were recorded with an accelerating voltage of $5 \mathrm{kV}$ and a working distance of $5 \mathrm{~mm}$.

Density and porosity

Density of the nanopapers $(\rho)$ was determined from their weight and their volume. The volume was taken as the product of the area and thickness. The thickness was measured using a digital caliper. Porosity of the nanopapers was calculated from their density by taking $1,500 \mathrm{~kg} \mathrm{~m}^{-3}$ as density for CNF ( $\left.\rho_{\mathrm{CNF}}\right)$ using Eq. (3) (Gibson and Ashby 1997). 
Porosity $=1-\frac{\rho}{\rho_{C N F}}$

Specific surface area and pore size distribution

The specific surface area of the nanopapers was determined according to the multipoint BrunauerEmmett-Teller (BET) method by $\mathrm{N}_{2}$ physisorption at relative vapor pressure of $0.05-0.2$ on a surface area and pore size analyser (Coulter SA3100, Beckman coulter Inc). Prior to each measurement, samples were degassed at $105{ }^{\circ} \mathrm{C}$ for $1 \mathrm{~h}$. Pore size distribution was determined from $\mathrm{N}_{2}$ desorption isotherm at relative vapor pressure of 0.35-0.99 following the BarrettJoyner-Halenda (BJH) model (Barrett et al. 1951).

\section{Dynamic vapor sorption (DVS)}

Moisture sorption measurements were obtained with a VTI-SA+ dynamic vapor sorption analyzer (DVS, TA-Instruments, New Castle, USA). A micro balance and a moisture generation system were placed in an incubator which maintained a constant temperature. A sample weighing ca. $10 \mathrm{mg}$ was placed in the sample cup, and the weight of the sample compared to a reference empty cup was registered with a resolution of $0.1 \mu \mathrm{g}$ while the RH surrounding the cups was controlled. Samples were tested in the DVS at an average temperature of $23{ }^{\circ} \mathrm{C}$. The sample was first dried at $60{ }^{\circ} \mathrm{C}$ and $0 \% \mathrm{RH}$ for $1 \mathrm{~h}$ followed by equilibration at $23{ }^{\circ} \mathrm{C}$. Then the moisture was set to 25, 50 and $85 \%$ RH. A time of 120 min was systematically used at each step insuring equilibrium. The change in mass was calculated as the moisture ratio i.e. the mass of the water in the sample at equilibrium divided by the dry weight of the sample.

\section{Contact angle}

The static sessile drop method was used to determine the contact angles of water on the CNF nanopaper surfaces with a Dataphysics OCA-20 contact angle analyzer (including Becton Dickison Syringe $1 \mathrm{ml}$, SS standard dispensing needle gauge $32 \mathrm{RW}$ ). The measurements were performed at $20{ }^{\circ} \mathrm{C}$ and at a RH of $65 \%$. To determine the contact angle, a $5 \mu \mathrm{l}$ droplet was placed on the specimen's surface. The drop image was processed by an image analysis system, which calculated both the left and right contact angles from the shape of the drop with an accuracy of $\pm 0.1^{\circ}$. The contact angle was taken as an average of two measurements, each being obtained as an average of the left and right contact angles of the water drop.

Dynamic mechanical analysis (DMA) in controlled RH

Dynamic mechanical analysis was carried out on a Q800 DMA analyzer (TA Instruments, USA) in tension mode. Specimens used had $4 \mathrm{~mm}$ in width, and the distance between clamps was ca. $10 \mathrm{~mm}$. The samples were first equilibrated at $25{ }^{\circ} \mathrm{C}$ and $0 \% \mathrm{RH}$ for $2 \mathrm{~h}$. Subsequently, RH scan was performed from $0 \% \mathrm{RH}$ to $95 \% \mathrm{RH}$ at a rate of $1 \% \mathrm{RH} \min ^{-1}$, a frequency of $1 \mathrm{~Hz}$ and a strain of $10 \mu \mathrm{m}$. Then, the samples were equilibrated at $95 \% \mathrm{RH}$ for $1 \mathrm{~h}$ at a frequency of $1 \mathrm{~Hz}$ and a strain of $10 \mu \mathrm{m}$.

Tensile mechanical properties

Tensile mechanical properties were performed on a horizontal tensile stage equipped with a $50 \mathrm{~N}$ load cell. Specimen strips having a width of $4 \mathrm{~mm}$ and a length of $30 \mathrm{~mm}$ (gauge length was $20 \mathrm{~mm}$ ) were placed in the tensile stage at a RH of $50 \%$, and stretched at a speed of $10 \% \mathrm{~min}^{-1}$ until rupture. For the wet tensile properties, a drop of water (ca $50 \mu \mathrm{l}$ ) was placed in the middle of the sample and distributed throughout its whole width. The wetting was performed for $60 \mathrm{~s}$ before stretching the sample at a speed of $10 \% \mathrm{~min}^{-1}$ until rupture. 3 specimens were tested per sample and the results were averaged for each test. The strength is taken as the stress at specimen breakage, and the stiffness is calculated from the initial linear region. Wet strength and stiffness were calculated with respect to the geometry of the initial dry sample.

\section{Results and discussion}

Characterization of CNF and elaboration of esterified nanopapers

Unmodified CNF were used as starting materials in this study. CNF were produced by mechanical disintegration of oat straw pulp powder. The morphology of the resulting nanofibers was then examined with SEM 


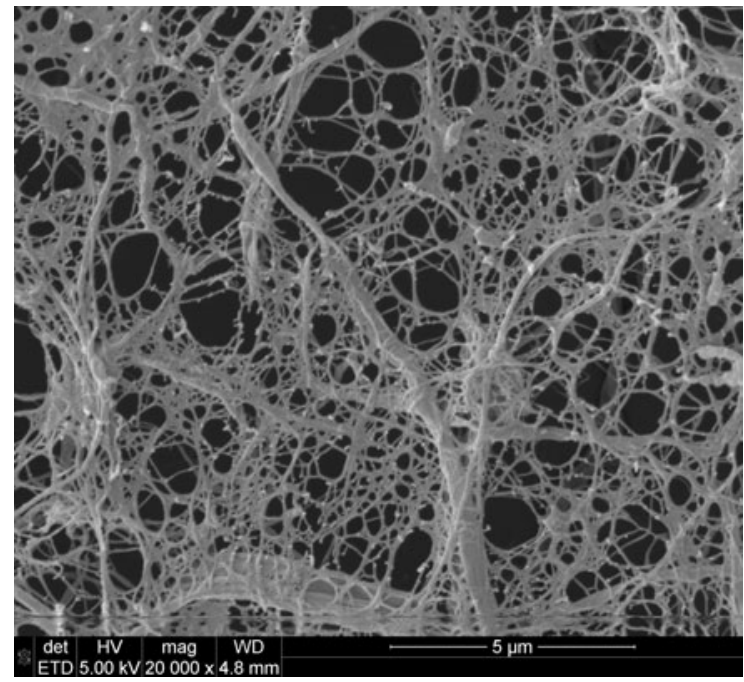

Fig. 1 SEM micrograph of unmodified CNF

(Fig. 1). Characteristic fiber network structures with nanofibrils diameter in the range of 30-90 nm were observed. However, nanofibril aggregates with diameters up to the micrometer size were also observed, as already reported in previous studies for CNF isolated from pulp without pre-treatment (Zimmermann et al. 2010).

The esterification of cellulose hydroxyl groups has been widely used over the last years to decrease the surface polarity and hygroscopicity of cellulosic fibers and nanofibers (Missoum et al. 2012; Bledzki and Gassan 1999). Accordingly in this study, anhydride molecules possessing alkyl side chains of different lengths have been used for the esterification of CNF. The reaction was conducted on wet cellulosic "cakes", which were obtained after CNF filtration and subsequent solvent exchange from water to acetone. These materials were then immersed in the anhydride liquid before being hot pressed in an oven at $80{ }^{\circ} \mathrm{C}$ for $120 \mathrm{~min}$. During the hot-pressing stage, strong interactions between nanofibrils developed owing to the formation of hydrogen bonds and other secondary interactions between fibrils. The esterification reaction is therefore expected to lower the $\mathrm{OH}$ groups content at the nanofibers surface and to some extent hinder the nanopaper formation process. Although employing simple steps without use of harmful solvents, this procedure is longer than other procedures reported earlier (Missoum et al. 2012; Rodionova et al. 2011). We expect that performing solvent exchange and washing steps for only few hours may considerably shorten the preparation time of the present hydrophobic nanopaper. Furthermore, it is also possible to use a single anhydride and change the reaction conditions in order to optimize and control the reaction extent, and this may be investigated in a future study. Esterified nanopapers have been denoted CNF-N where $\mathrm{N}$ represents the number of carbon in the grafted entity. In this nomenclature, $\mathrm{N}$ is equal to 2 , 4, 6 and 16 for the esterification with acetic, butyric, hexanoic and 2 dodecen-1-yl-succinnic anhydrides, respectively. The reference nanopaper is denoted CNF. The reaction schemes between hydroxyls at the surface of CNF and linear/cyclic anhydrides are shown in Fig. 2a, b, respectively. Two products are expected for the reaction with the 2 dodecen-1-ylsuccinnic anhydride.

The process envisaged in our study for the elaboration of esterified nanopapers presented several advantages. Vacuum filtration of CNF considerably lowered the water content of the suspension so that subsequent solvent exchange of the wet "cakes" to acetone was facilitated. All cellulose cakes kept a good mechanical integrity throughout the whole preparation process probably due to preservation of hydrogen bonding in the wet state, and were in a preformed shape so that subsequent pressing resulted in even films. Moreover, performing the reaction without prior oven drying of the CNF preserved the surface area of cellulose in the wet state, whereas an intermediate drying step would have resulted in the irreversible aggregation of CNF (i.e., hornification) and a subsequent decrease of hydroxyl group density available for chemical modification. Finally, the use of anhydride molecules for this reaction led to the liberation of mild acidic by-products when linear molecules were used (i.e., carboxylic acids) in the reaction medium which should not have impacted the cellulose integrity. No by-product was generated during the reaction with the cyclic anhydride.

\section{Surface analysis with FTIR-ATR and XPS analysis}

The surfaces of esterified nanofibers were first characterized with FTIR-ATR spectroscopy in order to assess the success of the reaction (Fig. 3). As compared with the spectrum of the reference sample, the characteristic vibrations of the grafted groups were 
(a)

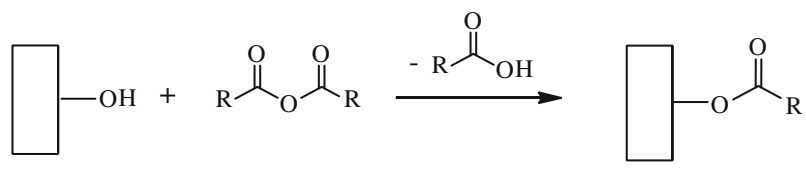

(b)
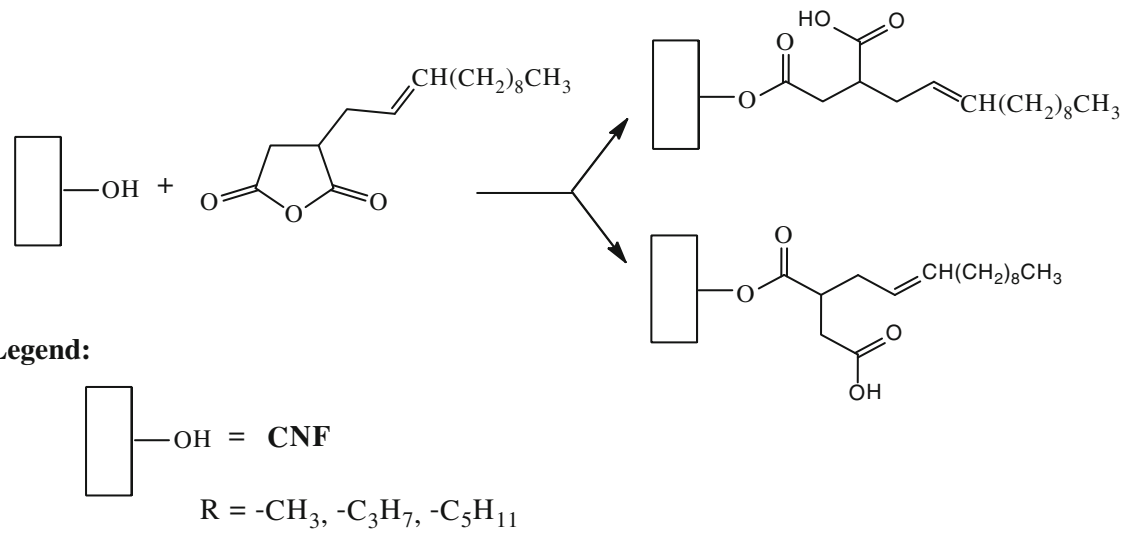

Fig. 2 Reaction schemes presenting the esterification of CNF with a linear symmetric anhydride molecules and $\mathbf{b}$ a cyclic non symmetric anhydride for which two products are expected

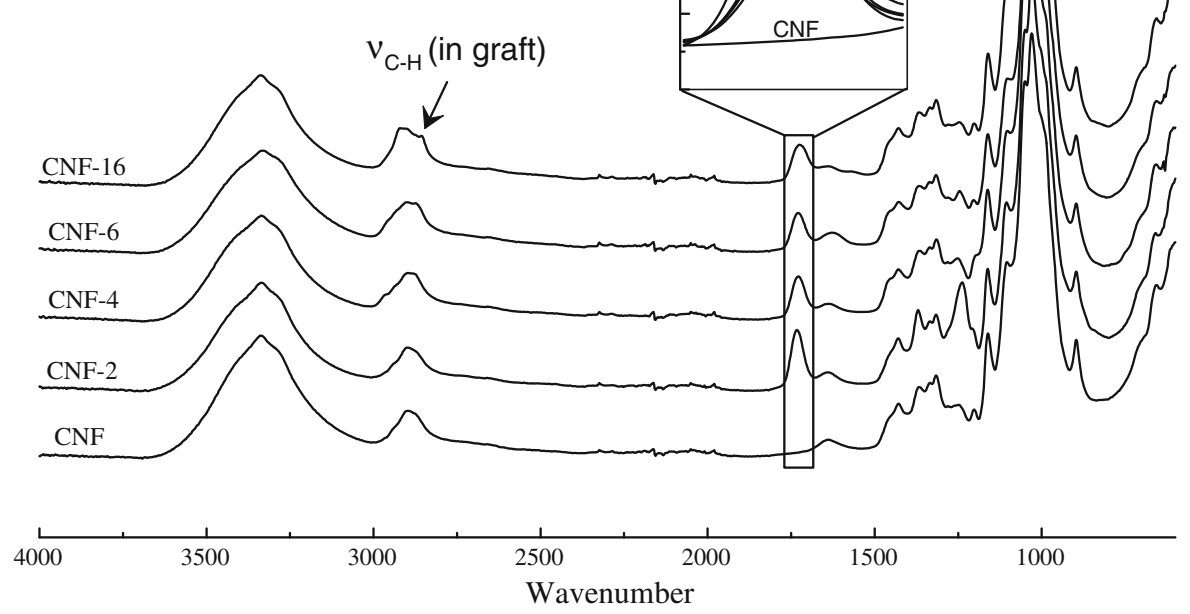

Fig. 3 FTIR spectra of reference and esterified CNF nanopapers. Zoom in the region 1,680-1,780 $\mathrm{cm}^{-1}$ shows the carbonyl peak for different CNF. The number next to each curve in the zoom indicates the number of carbons in the grafted entity

easily identified for the esterified samples and directly attributed on the corresponding spectra (Fig. 3). The intensity of the carbonyl stretching vibration at $1,730 \mathrm{~cm}^{-1}$ decreased with the length of the grafted alkyl chain entity (see corresponding zoom area in Fig. 3), which was tentatively associated with a progressive decrease of the nanopapers surface modification with the alkyl chain length of the anhydride.

The surfaces of the films were further analysed with XPS (Fig. 4). Low resolution XPS spectra are shown in Supplementary Information (S2). An O/C ratio of 0.8 was obtained for unmodified CNF. This value was 


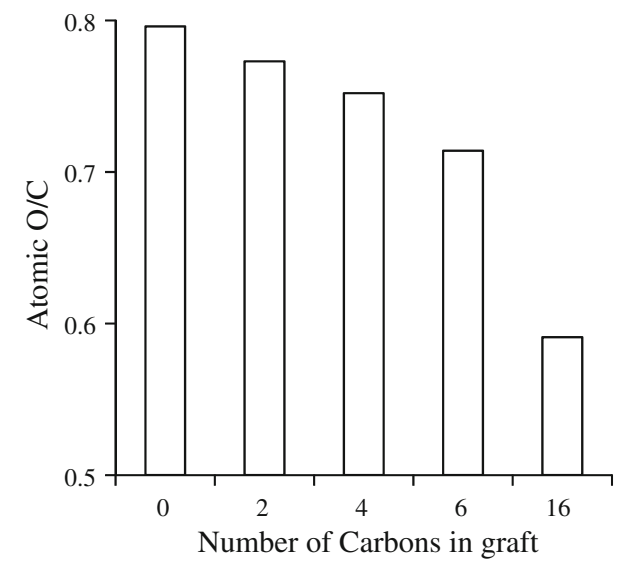

Fig. 4 Evolution of the $\mathrm{O} / \mathrm{C}$ ratio with the number of carbons attached to the grafted adduct ( 0 corresponds to the reference non-modified nanopaper). Results obtained from the XPS survey spectra of reference and esterified CNF nanopapers

slightly lower than the theoretical value of 0.83 for pure cellulose. This result has been associated with the presence of hemicelluloses and lignin on the surface of the nanofibers. This ratio progressively decreased with the number of the carbons attached to the grafted moieties, which indicated that the surface of the nanopapers became increasingly rich in hydrophobic carbon entities. These results will be discussed later when evaluating the wettability of the nanopapers towards liquid water (Fig. 10).

Bulk analysis with FTIR and elemental analysis

In order to assess the extent of the reaction in the bulk of the nanopapers, selected nanopapers (CNF, CNF-2 and CNF-16) have been grinded to a powder form and further analysed with FTIR spectroscopy in transmission mode with the $\mathrm{KBr}$ technique (see supplementary information S3). All signals previously attributed to the grafted groups with the ATR mode were also detected for the esterified grinded nanopaper in transmission, therefore suggesting that the reaction was not only limited to the surface but also occurred in the nanopaper bulk.

The success of the reaction was then further evaluated by subjecting unmodified and chemically modified nanopapers to elemental analysis (Fig. 5). A carbon weight content of $41.95 \%$ was measured for CNF. This value was slightly lower than the theoretical weight content of $44.4 \%$ for pure cellulose and was attributed to the presence of lignin and hemicelluloses in the starting material. Our experimental carbon weight content value was then corrected with respect to the theoretical value of cellulose (44.44\%), as already reported elsewhere (Missoum et al. 2012), so that a substitution degree (DS) of modified CNF nanopapers could be estimated from their carbon weight content value (see supplementary information S1 for DS calculation details). As presented in Fig. 5a, the experimental carbon weight content of all esterified nanopapers was systematically higher than that of the reference sample and gradually increased with the number of carbons attached to the grafted entities. The evolution of the DS of the nanopapers with regards to the length of the alkyl chain grafted is presented in Fig. 5b. The DS gradually decreased with the number of carbons attached to the carbonyl group, in agreement with the results obtained from the surface analysis of the films with FTIR spectroscopy. These results have been associated with a decrease of the anhydride's reactivity and an increase of steric hindrance issues with the length of the alkyl chain of the reactant. The present DS values $(0.1-0.38)$ are consistent with a modification occurring at the surface
Fig. 5 a Evolution of the experimental carbon weight content in reference and esterified nanopapers with the number of carbons in the graft. Results obtained from elemental analysis.

b Evolution of the degree of substitution (DS) of esterified nanopapers with the number of carbons in the graft
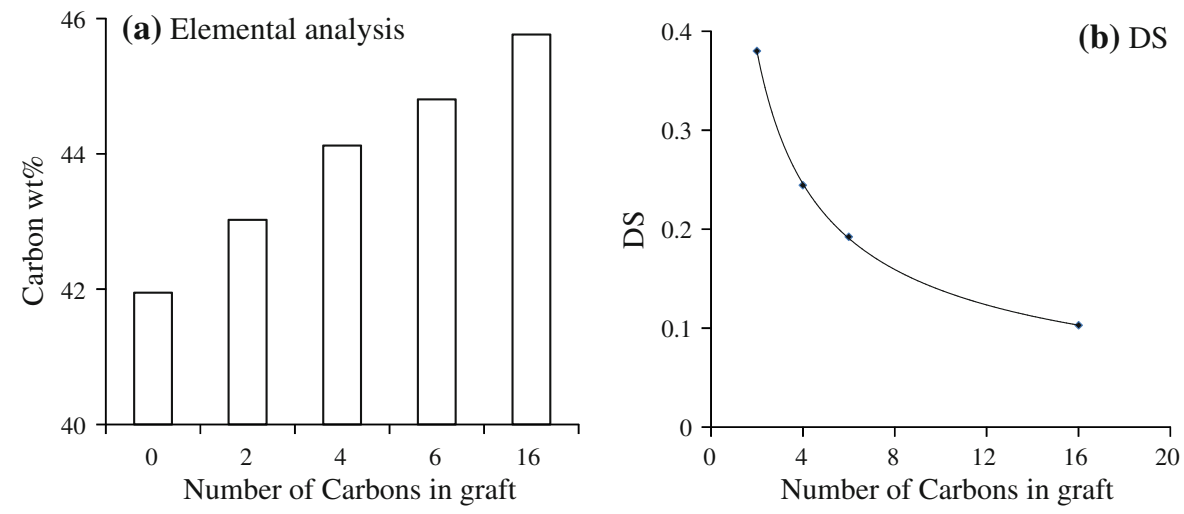


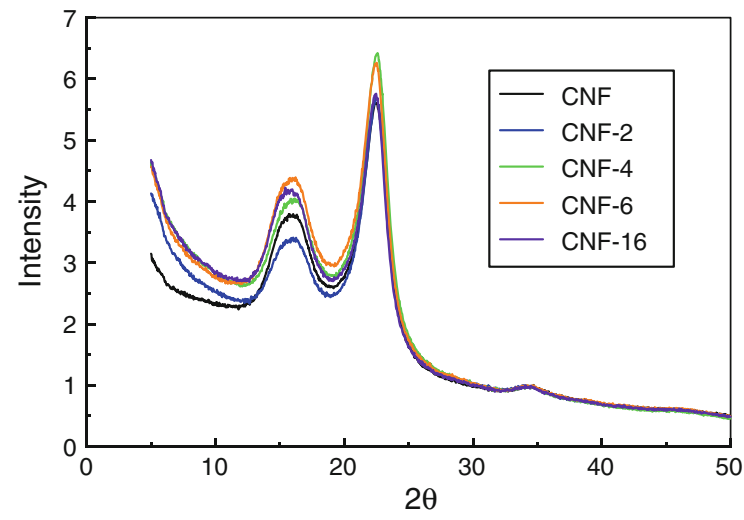

Fig. 6 XRD spectra of reference and esterified CNF nanopapers

Table 1 Crystallinity index (CI) for reference and esterified CNF nanopapers

\begin{tabular}{llllll}
\hline Sample & CNF & CNF-2 & CNF-4 & CNF-6 & CNF-16 \\
\hline CI & 53.9 & 57.2 & 56.8 & 53.1 & 53.2 \\
\hline
\end{tabular}

of the nanofibers. DS values between 0.2 and 0.3 were obtained for esterified nanofibers in ionic liquids (Missoum et al. 2012), while higher DS between 0.56 and 0.91 were obtained for acetylated nanofibers in a heterogeneous reaction (Rodionova et al. 2011).

X-ray diffraction analysis (XRD)

The impact of chemical modification on the fiber crystal structure was further evaluated using X-ray diffraction (WAXD) analysis (Fig. 6). Unmodified CNF displayed the typical X-ray diffraction pattern of native cellulose (cellulose I), with characteristic diffraction peaks at $2 \theta$ angles of $14.8^{\circ}, 16.6^{\circ}, 22.3^{\circ}$ and $34.4^{\circ}(101,10 \overline{1}, 002$ and 004 lattices, respectively) (Tingaut et al. 2010). After esterification, the original pattern of cellulose I could be found in all treated samples, which indicated that the original cellulose structure was maintained in all modified samples. In order to confirm this assumption, the crystallinity index (CI) of unmodified and esterified nanopapers was calculated by using the XRD peak height method (See experimental section) (Park et al. 2010). The results are presented in Table 1. As compared with the pristine sample, the CI of all esterified samples remained stable for all anhydrides envisaged in this study, therefore confirming that the treatment did not affect the crystal structure of CNF.

Scanning electron microscopy (SEM) analysis

The surface morphology of unmodified and esterified nanopapers was then characterized with SEM (Fig. 7). The fibrils in all nanopapers displayed a 2-D random in plane orientation characteristic of nanopapers prepared by a vacuum filtration process (Sehaqui et al. 2011d; Henriksson et al. 2008). Porosity could be seen in all samples with pore diameters in the range of 10-200 nm, as will be discussed in the next paragraph. Modified nanopapers seemed to have thicker fibrils and larger pores than reference nanopaper as a result of the grafted hydrophobic moieties. Thicker esterified CNF fibrils compared to reference CNF resulting in nanopapers with increased porosity were also reported by Missoum et al. (2012).

Density, porosity and surface area of $\mathrm{CNF}$ nanopapers

Density, porosity and surface area of CNF nanopapers prepared in this study are presented in Table 2. A direct comparison between unmodified and modified nanopapers must be taken with great care at this stage of the study, as the esterified films were first in contact with the anhydride and acetone, while the unmodified film was directly dried from ethanol.
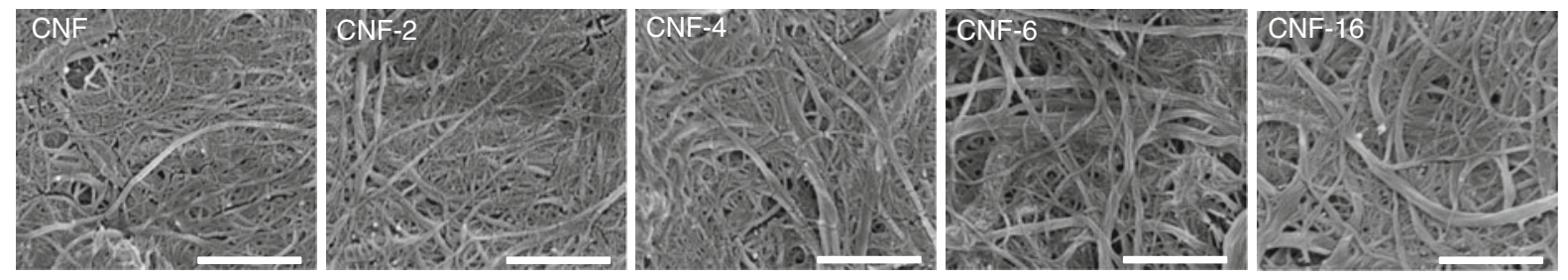

Fig. 7 SEM micrographs of the surface of reference and esterified CNF nanopapers. Scale bar is 1 micron 
Table 2 Density, porosity and surface area of reference and esterified CNF nanopapers

\begin{tabular}{lrrrrc}
\hline & CNF & CNF-2 & CNF-4 & CNF-6 & CNF-16 \\
\hline Density $\left(\mathrm{kg} \mathrm{m}^{-3}\right)$ & 506 & 658 & 570 & 551 & 415 \\
Porosity $(\%)$ & 66 & 56 & 62 & 63 & 72 \\
Surface area $\left(\mathrm{m}^{2} \mathrm{~g}^{-1}\right)$ & 57 & 38 & 39 & 28 & 47 \\
\hline
\end{tabular}

Moreover, different DS values were obtained for the functionalized nanopapers which restrict the conclusions arising from the impact of the chain length on the properties of the films. Nevertheless, clear trends can be distinguished from the obtained results.

A high porosity value of $66 \%$ has been measured for the reference CNF nanopaper and confirmed the possibility to introduce porosity into a CNF film by replacing water with a less polar organic solvent before drying. As reported by Henriksson et al., drying CNF from organic solvents instead of water results in lower capillary forces acting on the fibrils and a subsequent higher porous nanopaper structure (Henriksson et al. 2008). Concerning the modified nanopapers, the porosity gradually increased with the alkyl chain length of the graft with a concomitant decrease of the density of the nanopapers, so that a porosity as high as $72 \%$ could be achieved for the CNF-16 nanopaper. This trend was tentatively attributed to the progressive reduction of polarity and steric hindrance of the grafted groups with the length of the grafted alkyl chain, which may have reduced the possibility of hydrogen bonding between neighbouring nanofibers in the modified nanopapers.

Relatively high surface areas were obtained for the unmodified and esterified nanopapers, with values ranging from 28 to $57 \mathrm{~m}^{2} / \mathrm{g}$. The highest surface area has been measured for the unmodified nanopaper while all chemically modified ones showed lower values. Among these functionalized nanopapers, CNF-16 presented the highest surface area, which corroborated well with the density and porosity values obtained for this sample. Once again, a comparison of the surface area between samples seems to be difficult for the reasons stated at the beginning of the paragraph. Moreover, the chemical modification is expected to result in two opposite tendencies towards the evolution of the specific surface area. Hence, thicker fibrils and limited CNF aggregation upon drying are expected after functionalization, which

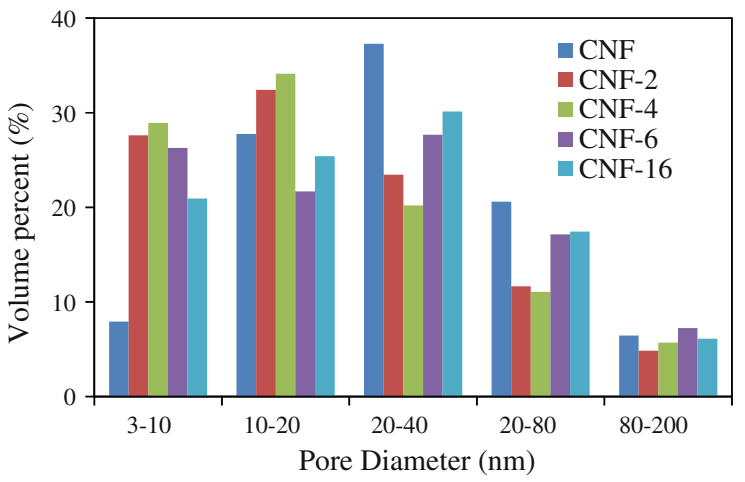

Fig. 8 Pore size distribution in reference and esterified nanopapers

should respectively lead to a decrease and increase of the resulting specific surface area of the nanopapers.

The pore size distribution in the nanopapers was then evaluated from their $\mathrm{N}_{2}$ desorption isotherms, the present gas sorption method being limited to pore sizes below $200 \mathrm{~nm}$. According to the IUPAC classification (Rouquerol et al. 1994), all the sorption isotherms are of type IV which involves adsorption on mesoporous adsorbents with strong adsorbate-adsorbent interaction (See supplementary information S4). Most of the pores were below $80 \mathrm{~nm}$ (Fig. 8). Furthermore, CNF6 and CNF-16 nanopapers displayed a higher proportion of pores with diameters above $40 \mathrm{~nm}$ than CNF-2 and CNF-4 nanopapers, in agreement with SEM observations. Interestingly, the contribution of pores with diameters below $10 \mathrm{~nm}$ increased from $8 \%$ in the reference nanopapers to more than $20 \%$ in the chemically modified ones. Consequently, the present nanopapers, combining high porosity, high surface area and nanopores may be of interest in membrane applications (e.g., nanofiltration or ultrafiltration). On the other hand, the porous character of these nanopapers is expected to decrease their water vapour and gas barrier performances, and alternative preparation methods of esterified nanopapers with lower porosity (e.g., by drying from water or by hot pressing at elevated pressure) should be pursued for barrier purposes.

Moisture uptake

The impact of the chemical functionalization onto the moisture uptake of the nanopapers has been studied by 


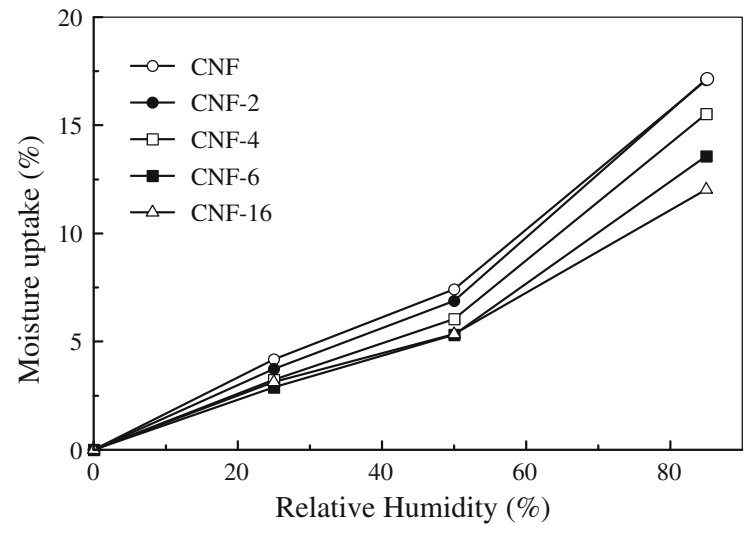

Fig. 9 Evolution of the moisture uptake with relative humidity for reference and modified nanopapers

dynamic vapour sorption (DVS) analysis at $0,25,50$ and $85 \%$ RH. The results are presented in Fig. 9. At low $\mathrm{RH}$, a monolayer of bounded water is present at the surface of the samples. By increasing $\mathrm{RH}$, additional layers of water molecules are deposited onto this layer. For the highest RH envisaged, the water vapour pressure is close to the saturation point and capillary condensation of water in nanopaper pores may occur (Banik and Bruckle 2010).

Similar moisture sorption patterns were observed in all samples, including unmodified nanopaper. The moisture uptake gradually increased with the increase in $\mathrm{RH}$, the highest increment being observed in all samples for the highest RHs envisaged in this study. In the entire RH range, a lower water sorption has been measured for all esterified samples as compared with the reference material, the moisture sorption decreasing with the length of the alkyl chain in the graft (i.e., from CNF to CNF-16). This trend has been related with a progressive decrease of the hygroscopic character of the nanopapers with their content of hydrophobic carbon moieties, as already seen by elemental analysis (see Fig. 5a).

\section{Wetting characteristics}

The change in surface polarity from the reference to the functionalized nanopapers was evaluated with static water contact angle measurements (Fig. 10). The neat CNF film presented a very low contact angle value of $24^{\circ}$, as expected due the hydrophilic character of CNF. The contact angle increased with the alkyl chain length in the grafts and correlated well with the

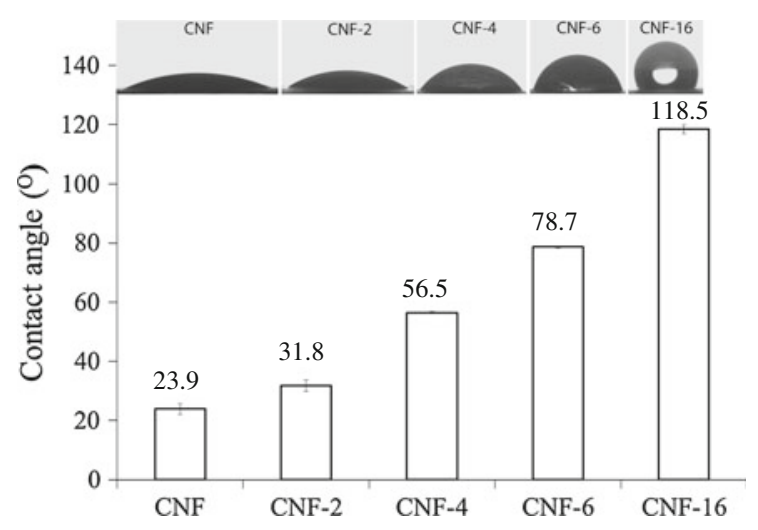

Fig. 10 Static water contact angle for reference and esterified nanopapers

progressive increase of low polarity moieties on the surface of the nanopapers as shown by XPS analysis (Fig. 4). A maximum contact angle of $118^{\circ}$ has even been reached for CNF-16, this hydrophobic nanopaper being able to float on the surface of water for several weeks while the reference CNF nanopaper sunk (see video in supplementary information).

High water contact angle values have already been reported for esterified nanopapers, with values of $56^{\circ}$ and $105^{\circ}$ for CNF films modified with acetic and hexanoic anhydride molecules, respectively (Missoum et al. 2012), and $83^{\circ}$ for acetylated CNF of high DS (Rodionova et al. 2011). The maximum contact angle value of $118^{\circ}$ reached in our case is comparable to modified CNF with octylamine (Johnson et al. 2011). There is also the possibility to obtain hydrophobic/superhydrophobic behaviour by modifying the paper instead of modifying the cellulose, as has been reported by Sousa and Mano (2013) who applied patterning of paper substrates to achieve superhydrophobicity and a maximum contact angle of $156^{\circ}$.

\section{Mechanical properties}

The mechanical properties of unmodified and esterified nanopapers were first evaluated using DMA in tensile mode, in a controlled humidity chamber at a fixed temperature of $25^{\circ} \mathrm{C}$. The evolution of the storage modulus data of the nanopapers over a $\mathrm{RH}$ range from 0 to $95 \%$ are shown in Fig. 11a. The equilibrium storage modulus in the dry state and at $95 \% \mathrm{RH}$ varied between $1.2-3.3 \mathrm{GPa}$ and 336-705 MPa, respectively. The storage modulus 

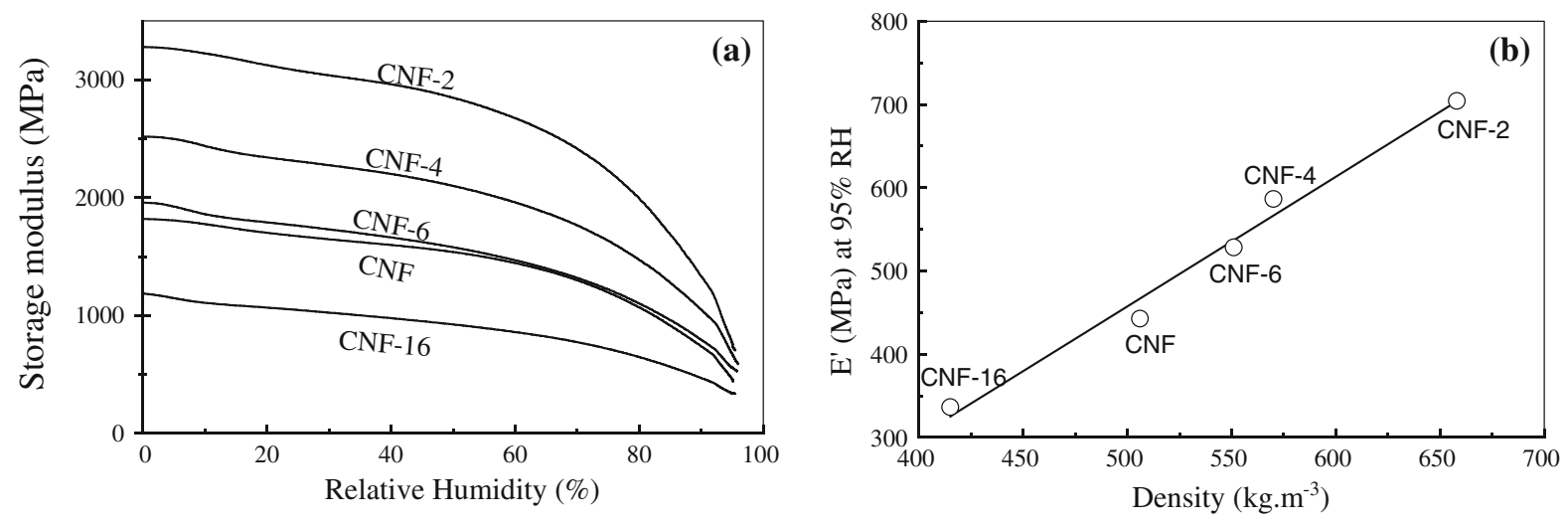

Fig. 11 a Evolution of the storage modulus of reference and esterified CNF nanopapers with relative humidity. b Evolution of the storage modulus at $95 \% \mathrm{RH}$ with the density of reference and esterified $\mathrm{CNF}$ nanopapers

progressively decreased with the RH for all nanopapers envisaged in this study. Indeed, softening takes place as the RH increases from 0 to $95 \% \mathrm{RH}$ since adsorbed water onto CNF (particularly in the disordered regions of CNF) acted as a "plasticizer". Similar trend was also observed for the evolution of the storage modulus of CNF foam over a wide humidity range (Svagan et al. 2008).

Generally, the elastic modulus of a fiber network depends on factors such as fiber orientation, fiber stiffness and network interconnectivity which is often expressed through the density (Kulachenko et al. 2012). In the present case, fiber orientation was random for all samples, and stiffness of single nanofibrils may have only slightly varied after chemical modification since crystallinity was not considerably altered (see XRD data in Fig. 6; Table 1). Accordingly in our study, density apparently had the major influence on the modulus of CNF nanopapers as suggested from Fig. 11b where the equilibrium storage modulus at $95 \% \mathrm{RH}$ scaled well with the density of the nanopapers. Indeed, CNF-2 has the best performance and the highest density, while CNF-16 has both the lowest performance and density. Consequently, the density seems to have a major influence onto the storage modulus of the present nanopapers, although other mechanisms may have a less noticeable influence.

Static tensile tests were also performed to evaluate the impact of the chemical modification on the mechanical properties of CNF nanopapers. Tensile stiffness and strength properties of the nanopapers in the dry and wet states (i.e., at $50 \% \mathrm{RH}$ and in liquid water respectively) are presented in Table 3. Properties of the present nanopapers are lower than values reported for low porosity nanopaper dried from water (dry strength and stiffness of $\sim 220 \mathrm{MPa}$ and $13 \mathrm{GPa}$, respectively vs wet strength and stiffness of 20 and $625 \mathrm{MPa}$, respectively) (Sehaqui et al. 2010a, 2013; Henriksson et al. 2008), which has been attributed to the higher porosity of the present samples. The modulus at $50 \% \mathrm{RH}\left(\mathrm{E}_{\mathrm{dry}}\right)$ increased with the density of the corresponding nanopaper in agreement with results in Fig. 11b (See supplementary information S5a). The modulus in the wet state, however, was strongly influenced by the wettability of the nanopaper, and increased with the alkyl chain length in the grafts (See supplementary information S5b).

In the dry state, tensile strength (in Pascal) of nanofiber networks is mainly affected by the nanofiber and bonding strengths, bonded area, and presence of porosity (Page 1969). Bonding strength of esterified CNF may result in lower dry strength of the nanopapers, but this is difficult to verify due to variability of other parameters (e.g., porosity). In the wet state, wetting properties of the nanopaper additionally influence its strength. CNF-16 nanopaper presented the highest wet strength although presenting the highest porosity, thus illustrating the important effect of nanopapers wetting property onto their wet strength. When hydrophobicity is increased, the water penetration susceptibility goes down which favour increased wet strength, however it may also remove $\mathrm{H}$-bonding possibility which in turn should decrease the dry strength. 
Table 3 Dry strength $\left(\sigma_{\text {dry }}\right)$ and wet strength $\left(\sigma_{\text {wet }}\right)$ properties of reference and modified nanopapers

\begin{tabular}{lrrrcc}
\hline & CNF & CNF-2 & CNF-4 & CNF-6 & CNF-16 \\
\hline $\mathrm{E}_{\text {dry }}(\mathrm{MPa})$ & $890(95)$ & $2,049(113)$ & $1,515(30)$ & $1,048(68)$ & $522(70)$ \\
$\sigma_{\text {dry }}(\mathrm{MPa})$ & $25.5(3.0)$ & $45.6(2.8)$ & $23.0(1.4)$ & $18.6(0.9)$ & $13.6(1.7)$ \\
$\mathrm{E}_{\text {wet }}(\mathrm{MPa})$ & $18.9(2.3)$ & $44.5(4.3)$ & $52.0(11.0)$ & $136.0(40.0)$ & $264.0(19.1)$ \\
$\sigma_{\text {wet }}(\mathrm{MPa})$ & $1.2(0.1)$ & $2.8(0.2)$ & $1.8(0.1)$ & $2.1(0.1)$ & $4.4(0.8)$ \\
\hline
\end{tabular}

Values in parenthesis represent standard deviation
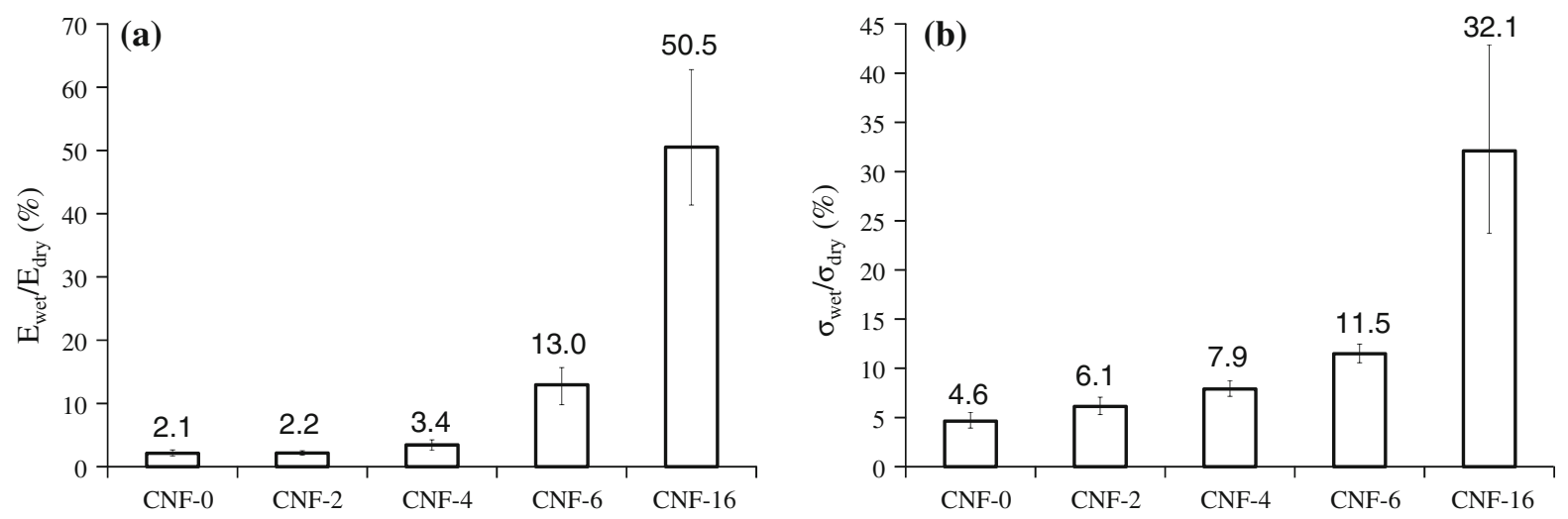

Fig. 12 a Wet by dry stiffness ratio of reference and modified nanopapers. b Wet by dry strength ratio of reference and modified nanopapers. Wetting time is $60 \mathrm{~s}$

In order to compare strength and stiffness reduction of CNF nanopapers due to wetting, wet strength and stiffness were normalised with respect to the dry values. The results are presented in Fig. 12. The reference nanopaper presented, as expected, a low wet strength and stiffness of only 4.6 and $2.1 \%$ of its dry strength and stiffness, respectively. In the reference nanopaper, water readily penetrated the sample thus weakening interfibril bonds so that the sample breaks at low stress value. The hydrophobic moieties introduced on the surface and in the bulk of the films improved their wet strength since water penetration into the sample was much reduced. The wet by dry strength and stiffness ratios progressively increased with the carbon chain length of the grafted moieties. CNF-16 nanopaper displayed a wet strength and stiffness of 32 and $50 \%$ of its dry strength and stiffness, respectively, which constituted a 7 - and 24 -fold improvement compared to the reference $\mathrm{CNF}$ nanopaper. The esterification is thus an effective approach to hydrophobize nanopapers and further improve their strength and stiffness properties in wet environments.

\section{Conclusion}

In the quest for CNF films with improved moisture durability, CNF nanopapers holding alkyl chains of different lengths have been prepared. A mild esterification procedure without catalyst has been envisaged for the modification of nanopapers, using a preimpregnation step of a wet NFC cake in an anhydride/ acetone mixture, followed by a hot pressing step at $80{ }^{\circ} \mathrm{C}$ and finally a washing procedure. In these conditions, the crystalline structure of native cellulose in modified CNF could be preserved. The extent of the esterification reaction on $\mathrm{CNF}$, as deducted from the degree of substitution and from FTIR carbonyl peak intensity, decreased with the length of the grafted alkyl chain due to the lower reactivity of higher molar mass anhydrides. The nanopapers presented a high porosity between 56 and $72 \%$, an important surface area between 28 and $57 \mathrm{~m}^{2} / \mathrm{g}$, since they were dried from a less polar solvent than water. The moisture uptake of the nanopapers decreased with the length of the alkyl chain grafted which was attributed to the increase in hydrophobic carbon content. Wetting characteristics of the modified nanopapers differed considerably from 
those of reference nanopaper. The contact angle, initially at $24^{\circ}$ for the reference nanopaper, increased with the length of the grafted entity to reach $118^{\circ}$ for the nanopaper bearing the longest alkyl chain. The latter floated on the water surface while the reference CNF nanopaper sank. As a result, wet strength and stiffness of hydrophobic nanopaper exceeded those of reference nanopaper by 7 and 24 times, respectively, thus demonstrating the benefit of the chemical modification to tailor the mechanical properties of CNF nanopapers in wet environments.

Acknowledgments Esther Strub, Anja Huch, Roland Hauert and Beatrice Fischer from EMPA institute are thanked for their support with SEM, contact angle, XPS and FTIR, respectively. Mr. Michael Schneider from ETH-Mikrolabor is thanked for performing elemental analysis. Markus Rueggeberg from ETH/ EMPA is thanked for introduction to tensile test equipment.

\section{References}

Araki J, Wada M, Kuga S (2001) Steric stabilization of a cellulose microcrystal suspension by poly(ethylene glycol) grafting. Langmuir 17(1). doi:10.1021/la001070m

Aulin C, Salazar-Alvarez G, Lindstrom T (2012) High strength, flexible and transparent nanofibrillated cellulose-nanoclay biohybrid films with tunable oxygen and water vapor permeability. Nanoscale 4(20). doi:10.1039/c2nr31726e

Banik G, Bruckle I (2010) Principles of water absorption and desorption in cellulosic materials. Restaurator 31(3-4): 164-177. doi:10.1515/rest.2010.012

Barrett EP, Joyner LG, Halenda PP (1951) The determination of pore volume and area distributions in porous substances. I. Computations from nitrogen isotherms. J Am Chem Soc 73:373-380

Bledzki AK, Gassan J (1999) Composites reinforced with cellulose based fibres. Prog Polym Sci 24(2):221-274

Boujemaoui A, Carlsson L, Malmstrom E, Lahcini M, Berglund L, Sehaqui H, Carlmark A (2012) Facile preparation route for nanostructured composites: surface-initiated ringopening polymerization of epsilon-caprolactone from high-surface-area nanopaper. Acs Appl Mater Inter 4(6): 3191-3198. doi:10.1021/Am300537h

Cetin NS, Tingaut P, Oezmen N, Henry N, Harper D, Dadmun M, Sebe G (2009) Acetylation of cellulose nanowhiskers with vinyl acetate under moderate conditions. Macromol Biosci 9(10). doi:10.1002/mabi.200900073

Cheng Q, Wang S, Harper DP (2009) Effects of process and source on elastic modulus of single cellulose fibrils evaluated by atomic force microscopy. Compos Part A Appl Sci Manuf 40(5). doi:10.1016/j.compositesa.2009.02.011

Fukuzumi H, Saito T, Wata T, Kumamoto Y, Isogai A (2009) Transparent and high gas barrier films of cellulose nanofibers prepared by TEMPO-mediated oxidation. Biomacromolecules 10(1):162-165. doi:10.1021/bm801065u
Gebald C, Wurzbacher JA, Tingaut P, Zimmermann T, Steinfeld A (2011) Amine-based nanofibrillated cellulose as adsorbent for $\mathrm{CO} 2$ capture from air. Environ Sci Technol 45(20):9101-9108. doi:10.1021/es202223p

Gibson LJ, Ashby MF (1997) Cellular solids: structure and properties, 2nd edn. Cambridge University Press, Cambridge, p 56

Gindl WA, Veigel S, Obersriebnig M, Tippelreither C, Keckes J (2012) High-modulus oriented cellulose nanopaper. In: Sources FMfR (ed). American Chemical Society, p 13

Gousse C, Chanzy H, Excoffier G, Soubeyrand L, Fleury E (2002) Stable suspensions of partially silylated cellulose whiskers dispersed in organic solvents. Polymer 43(9). doi:10.1016/s0032-3861(02)00051-4

Habibi Y, Dufresne A (2008) Highly filled bionanocomposites from functionalized polysaccharide nanocrystals. Biomacromolecules 9(7):1974-1980. doi:10.1021/Bm8001717

Habibi Y, Goffin AL, Schiltz N, Duquesne E, Dubois P, Dufresne A (2008) Bionanocomposites based on poly(epsiloncaprolactone)-grafted cellulose nanocrystals by ringopening polymerization. J Mater Chem 18(41):5002-5010. doi:10.1039/B809212e

Henriksson M, Henriksson G, Berglund LA, Lindstrom T (2007) An environmentally friendly method for enzyme-assisted preparation of microfibrillated cellulose (MFC) nanofibers. Eur Polym J 43:3434-3441. doi:10.1016/j.eurpolymj. 2007.05.038

Henriksson M, Berglund LA, Isaksson P, Lindstrom T, Nishino T (2008) Cellulose nanopaper structures of high toughness. Biomacromolecules 9(6):1579-1585. doi:10.1021/ bm800038n

Ho TTT, Ko YS, Zimmermann T, Geiger T, Caseri W (2012a) Processing and characterization of nanofibrillated cellulose/layered silicate systems. J Mater Sci 47(10):43704382. doi:10.1007/s10853-012-6291-8

Ho TTT, Zimmermann T, Ohr S, Caseri WR (2012b) Composites of cationic nanofibrillated cellulose and layered silicates: water vapor barrier and mechanical properties. Acs Appl Mater Inter 4(9):4832-4840. doi:10.1021/am3011737

Johnson RK, Zink-Sharp A, Glasser WG (2011) Preparation and characterization of hydrophobic derivatives of TEMPOoxidized nanocelluloses. Cellulose 18(6). doi:10.1007/ s10570-011-9579-y

Kulachenko A, Denoyelle T, Galland S, Lindstrom SB (2012) Elastic properties of cellulose nanopaper. Cellulose 19(3):793-807. doi:10.1007/s10570-012-9685-5

Lasseuguette E (2008) Grafting onto microfibrils of native cellulose. Cellulose 15(4):571-580. doi:10.1007/s10570-0089200-1

Littunen K, Hippi U, Johansson L-S, Osterberg M, Tammelin T, Laine J, Seppala J (2011) Free radical graft copolymerization of nanofibrillated cellulose with acrylic monomers. Carbohydr Polym 84(3):1039-1047. doi:10.1016/j.carbpol. 2010.12.064

Liu A, Walther A, Ikkala O, Belova L, Berglund LA (2011) Clay nanopaper with tough cellulose nanofiber matrix for fire retardancy and gas barrier functions. Biomacromolecules 12(3):633-641. doi:10.1021/bm101296z

Missoum K, Belgacem MN, Barnes J-P, Brochier-Salon M-C, Bras J (2012) Nanofibrillated cellulose surface grafting in ionic liquid. Soft Matter 8(32). doi:10.1039/c2sm25691f 
Nelson M, O'Connor R (1964) Relation of certain infrared bands to cellulose crystallinity and crystal lattice type. Part II. A new infrared ratio for estimation of crystallinity in celluloses I and II. J Appl Polym Sci 8:1325-1341

Nogi M, Iwamoto S, Nakagaito AN, Yano H (2009) Optically transparent nanofiber paper. Adv Mater 21(16):15951598. doi:10.1002/adma.200803174

Österberg M, Vartiainen J, Lucenius J, Hippi U, Seppälä J, Serimaa R, Laine J (2013) A fast method to produce strong NFC films as a platform for barrier and functional materials. Acs Appl Mater Inter 5(11):4640-4647. doi:10.1021/ am401046x

Paakko M, Ankerfors M, Kosonen H, Nykanen A, Ahola S, Osterberg M, Ruokolainen J, Laine J, Larsson PT, Ikkala O, Lindstrom T (2007) Enzymatic hydrolysis combined with mechanical shearing and high-pressure homogenization for nanoscale cellulose fibrils and strong gels. Biomacromolecules 8(6):1934-1941. doi:10.1021/bm06 $1215 \mathrm{p}$

Paakko M, Vapaavuori J, Silvennoinen R, Kosonen H, Ankerfors M, Lindstrom T, Berglund LA, Ikkala O (2008) Long and entangled native cellulose I nanofibers allow flexible aerogels and hierarchically porous templates for functionalities. Soft Matter 4(12):2492-2499. doi:10.1039/ b810371b

Page DH (1969) A theory for tensile strength of paper. Tappi 52(4):674

Park S, Baker JO, Himmel ME, Parilla PA, Johnson DK (2010) Cellulose crystallinity index: measurement techniques and their impact on interpreting cellulase performance. Biotechnol Biofuels 3(1):1-10

Rodionova G, Lenes M, Eriksen O, Gregersen O (2011) Surface chemical modification of microfibrillated cellulose: improvement of barrier properties for packaging applications. Cellulose 18(1). doi:10.1007/s10570-010-9474-y

Rouquerol J, Avnir D, Fairbridge CW, Everett DH, Haynes JH, Pernicone N, Ramsay JDF, Sing KSW, Unger KK (1994) Recommendations for the characterization of porous solids. Pure Appl Chem 66(8):1739-1758

Saito T, Kimura S, Nishiyama Y, Isogai A (2007) Cellulose nanofibers prepared by TEMPO-mediated oxidation of native cellulose. Biomacromolecules 8(8):2485-2491. doi: $10.1021 / \mathrm{bm} 0703970$

Saito T, Hirota M, Tamura N, Kimura S, Fukuzumi H, Heux L, Isogai A (2009) Individualization of nano-sized plant cellulose fibrils by direct surface carboxylation using TEMPO catalyst under neutral conditions. Biomacromolecules 10(7):1992-1996. doi:10.1021/bm900414t

Saito T, Uematsu T, Kimura S, Enomae T, Isogai A (2011) Selfaligned integration of native cellulose nanofibrils towards producing diverse bulk materials. Soft Matter 7(19): 8804-8809. doi:10.1039/c1sm06050c

Sehaqui H, Liu AD, Zhou Q, Berglund LA (2010a) Fast preparation procedure for large, flat cellulose and cellulose/ inorganic nanopaper structures. Biomacromolecules 11(9): 2195-2198. doi:10.1021/bm100490s

Sehaqui H, Salajkova M, Zhou Q, Berglund LA (2010b) Mechanical performance tailoring of tough ultra-high porosity foams prepared from cellulose I nanofiber suspensions. Soft Matter 6(8):1824-1832. doi:10.1039/ b927505c
Sehaqui H, Allais M, Zhou Q, Berglund LA (2011a) Wood cellulose biocomposites with fibrous structures at microand nanoscale. Compos Sci Technol 71(3):382-387. doi:10.1016/j.compscitech.2010.12.007

Sehaqui H, Berglund LA, Zhou Q (2011b) Strong and tough cellulose nanopaper with high specific surface area and porosity. Biomacromolecules 12(10):3638-3644

Sehaqui H, Zhou Q, Berglund LA (2011c) High-porosity aerogels of high specific surface area prepared from nanofibrillated cellulose (NFC). Compos Sci Technol 71(13): 1593-1599. doi:10.1016/j.compscitech.2011.07.003

Sehaqui H, Zhou Q, Berglund LA (2011d) Nanostructured biocomposites of high toughness-a wood cellulose nanofiber network in ductile hydroxyethylcellulose matrix. Soft Matter 7(16):7342-7350. doi:10.1039/c1sm05325f

Sehaqui H, Morimune S, Nishino T, Berglund LA (2012a) Stretchable and strong cellulose nanopaper structures based on polymer-coated nanofiber networks: an alternative to nonwoven porous membranes from electrospinning. Biomacromolecules 13(11). doi:10.1021/bm301105s

Sehaqui H, Mushi NE, Morimune S, Salajkova M, Nishino T, Berglund LA (2012b) Cellulose nanofiber orientation in nanopaper and nanocomposites by cold drawing. Acs Appl Mater Interfaces 4(2):1043-1049. doi:10.1021/ am2016766

Sehaqui H, Zhou Q, Berglund L (2013) Nanofibrillated cellulose for enhancement of strength in high-density paper structures. Nord Pulp Pap Res J 28(2): 182

Siqueira G, Bras J, Dufresne A (2009) Cellulose whiskers versus microfibrils: influence of the nature of the nanoparticle and its surface functionalization on the thermal and mechanical properties of nanocomposites. Biomacromolecules 10(2): 425-432. doi:10.1021/Bm801193d

Sousa M, Mano J (2013) Patterned superhydrophobic paper for microfluidic devices obtained by writing and printing. Cellulose 20(5):2185-2190. doi:10.1007/s10570-0139991-6

Svagan AJ, Samir M, Berglund LA (2008) Biomimetic foams of high mechanical performance based on nanostructured cell walls reinforced by native cellulose nanofibrils. Adv Mater 20(7):1263-1269. doi:10.1002/adma.200701215

Taniguchi T, Okamura K (1998) New films produced from microfibrillated natural fibres. Polym Int 47(3):291-294

Tingaut P, Zimmermann T, Lopez-Suevos F (2010) Synthesis and characterization of bionanocomposites with tunable properties from poly(lactic acid) and acetylated microfibrillated cellulose. Biomacromolecules 11(2):454-464

Tingaut P, Hauert R, Zimmermann T (2011) Highly efficient and straightforward functionalization of cellulose films with thiol-ene click chemistry. J Mater Chem 21(40): 16066-16076. doi:10.1039/C1jm11620g

Tingaut P, Zimmermann T, Sebe G (2012) Cellulose nanocrystals and microfibrillated cellulose as building blocks for the design of hierarchical functional materials. J Mater Chem 22(38):20105-20111. doi:10.1039/C2jm32956e

Turbak AF, Snyder FW, Sandberg KR (1983) Microfibrillated cellulose, a new cellulose product: properties, uses, and commercial potential. J Appl Polym Sci: Appl Polym Symp 37:815-827

Yano H, Sugiyama J, Nakagaito AN, Nogi M, Matsuura T, Hikita M, Handa K (2005) Optically transparent 
composites reinforced with networks of bacterial nanofibers. Adv Mater 17(2):153-155. doi:10.1002/adma.2004 00597

Zimmermann T, Pohler E, Geiger T (2004) Cellulose fibrils for polymer reinforcement. Adv Eng Mater 6(9):754-761. doi:10.1002/adem.200400097
Zimmermann T, Bordeanu N, Strub E (2010) Properties of nanofibrillated cellulose from different raw materials and its reinforcement potential. Carbohydr Polym 79(4): 1086-1093. doi:10.1016/j.carbpol.2009.10.045 